\title{
Hypertrophic Pulmonary Osteoarthropathy with Positive Antinuclear Antibodies: Case Report
}

\author{
C. Cruz \\ M. Rocha \\ D. Andrade \\ F. Guimarães \\ V. Silva \\ S. Souza \\ C.A. Moura \\ C.G. Moura
}

Hospital Santo Antonio, Obras Sociais Irmã Dulce, Salvador, Brazil

\section{Key Words}

Hypertrophic pulmonary osteoarthropathy · Antinuclear antibodies · Bronchial adenocarcinoma

\begin{abstract}
A male Afro-descendant patient, 57 years old, complaining of polyarticular involvement and weight loss for 18 months, with a load of 13.5 pack years of smoking. On physical examination there was pain on palpation of the right knee and right leg, with signs of inflammation on the knee. We also observed digital clubbing in all fingers. Antinuclear antibodies (ANA) and anti-Sm antibodies were positive. X-rays of the legs and arm showed cortical thickening of long bones. The computed tomography demonstrated a large mass located in the middle lobe of the right lung. The anatomopathological study revealed a bronchial adenocarcinoma. The history of polyarticular involvement associated with positive anti-Sm and ANA antibodies could lead to an erroneous diagnosis of systemic lupus erythematosus. Considering the bad consequences of delayed diagnosis in this patient, the medical team should be alerted for suspecting and look for a lung cancer under these circumstances.
\end{abstract}

\section{Introduction}

The term 'pulmonary hypertrophic osteoarthropathy' (PHO) was proposed by Marie in 1890, while one year before Bamberger had described two patients with hypertrophic osteoarthropathy related to bronchiectasis [1]. PHO, also known as Pierre Marie-Bamberger Syndrome, is characterized by proliferative periostitis of long bones, digital clubbing, polyarticular or oligoarticular manifestations [2]. It is commonly associated with intrathoracic malignancies, and related to primary lung cancer in $80 \%$ 
of patients. According to the literature $0.2 \%$ to $17 \%$ of patients with lung cancer develop PHO [1]. The literature has described the syndrome in the absence of antinuclear antibodies.

Solans-Laqué et al. [3], nevertheless, have demonstrated antinuclear autoantibodies (ANA) in $27.7 \%$ of patients with malignancies when compared with only $6.4 \%$ in healthy subjects. Shoenfeld and colleagues [4] found anti-RNP and anti-Sm antibodies in $16(21.7 \%)$ and 14 lymphoma patients (20\%), respectively, significantly more than in the controls $(\mathrm{p}<0.05)$ in both antibodies. These findings were valid for those with Hodgkin and non-Hodgkin lymphoma.

We report herein a case of PHO with polyarticular involvement and detectable antinuclear and anti-Sm antibodies.

\section{Case Report}

A male, Afro-descendant 57-year-old complained of pain of strong intensity in the right ankle, right shoulder joints, and both knees with local edema eighteen months ago. The patient did not notice triggers of pain but had improvement with anti-inflammatory medicines. He did not mention alopecia, malar rash, photosensitivity, dark urine, decreased urine volume, seizures and behavior changes.

He observed weight loss of $11 \mathrm{~kg}$ in recent months, sporadic dry cough and an episode of coughing up bloody sputum a month ago. He is a former smoker and had quit smoking for 13 years, with a load of 13.5 pack years of smoking.

Laboratory tests requested on another rheumatologic clinic revealed: red blood cell counts $4,880,000 / \mathrm{ml}$, hemoglobin $10.2 \mathrm{~g} / \mathrm{dl}$, hematocrit $33.9 \%$, with negative Coombs, platelets $520,000 / \mathrm{ml}$, total leukocyte count $8,000 / \mathrm{ml}$, erythrocyte sedimentation rate $51 \mathrm{~mm} /$ first hour, urea $32 \mathrm{mg} / \mathrm{dl}$, creatinine $0.8 \mathrm{mg} / \mathrm{dl}$, AST $33 \mathrm{U} / \mathrm{l}$, ALT $20 \mathrm{U} / \mathrm{l}$, gamma-GT $107 \mathrm{U} / \mathrm{l}$, C-reactive protein $143.0 \mathrm{mg} / \mathrm{l}$, Waaler-Rose $256 \mathrm{IU} / \mathrm{ml}$, positive ANA 1/5,120 (speckled pattern), anti-DNA negative, anti-Sm 156 (repeated and confirmed in independent samples of serum), IgG and IgM serology for Epstein-Barr was negative; C3 171.0, C4 32.60, rheumatoid factor 429 IU/ml, normal urine exam, 24-hour proteinuria $216 \mathrm{mg}$.

On physical examination the patient was thin, afebrile, with digital clubbing in all fingers (fig. 1). Examination of skin showed no malar rash or alopecia. Oropharyngeal examination did not present ulcers. Osteoarticular apparatus: there was pain on palpation of the right knee and right leg, with signs of inflammation on the right knee. Respiratory system: reduced breath sounds in the lower twothirds of the right hemithorax without stertors and no pleural rub. Cardiovascular system: blood pressure $125 \times 75 \mathrm{~mm} \mathrm{Hg}$, HR $84 \mathrm{bpm}$, normal and rhythmic beats in two phases, with no murmurs and no pericardial rub. Neurological exam: no abnormal findings.

Among imaging tests performed, chest X-rays showed homogeneous opacity of partially defined contours, located in the anterior portions of the right lung basis. Computed tomography demonstrated a large mass $(10.0 \times 10.0 \mathrm{~cm}$ in greatest diameter $)$ with heterogeneous density at the expense of central necrosis, located in the middle lobe of the right lung (fig. 2 ). X-rays of the legs and arm showed cortical thickening of long bones (ig. 3 ).

Bronchoscopy showed in the right bronchial tree a vegetative tumor with friable coating almost completely obstructing the lumen of the bronchus. The anatomopathological study revealed a bronchial adenocarcinoma. 


\section{Discussion}

PHO has been described in the literature with negative ANA, but the presence of these antibodies has been related to cancer [3]. Madrid et al. [5] found that presence of ANA was consistent in most lung cancer patients in their casuistic in a dilution of up to $1: 500$.

The significance of antinuclear antibodies in malignancies is not well understood according to Zuber [6]. The antigens may be specific to each type of tumor and the production of antibodies would be an attempt to neutralize them. Cancer patients may develop many kinds of autoantibodies resulting from tissue damage and necrosis, allowing the generation of proteins that are usually not recognized by the immune system.

The occurrence of articular involvement with positive ANA and anti-Sm is the unusual presentation in this case report.

Anti-Sm antibodies (ELISA) have been pointed out as having a high specificity for lupus diagnosis (95-98\%) [6]. False positives have been reported in cases of Hodgkin and non-Hodgkin lymphoma [4], rheumatoid arthritis [7], infection with Epstein-Barr virus [8], Malaysian ethnicity [9], relatives of schizophrenics and schizophrenics [10].

Considering the size of the mass $(10.0 \times 10.0 \mathrm{~cm}$ in greatest diameter $)$, it is reasonable to assume that lung cancer was already present when the patient developed severe pain involving the right ankle, right shoulder and both knees eighteen months before hospitalization. This temporal relationship between the malignancy and the appearance of osteoarticular signs and symptoms according to McLean [11] reinforces the diagnosis of a paraneoplastic syndrome.

The history of polyarticular involvement associated with positive anti-Sm and ANA could lead to an erroneous diagnosis of systemic lupus erythematosus, since these antibodies are highly specific for the diagnosis of this disease. Considering the bad consequences of delayed diagnosis in a patient with bronchial adenocarcinoma, the medical team should be alerted for suspecting and look for a lung cancer under these circumstances. 

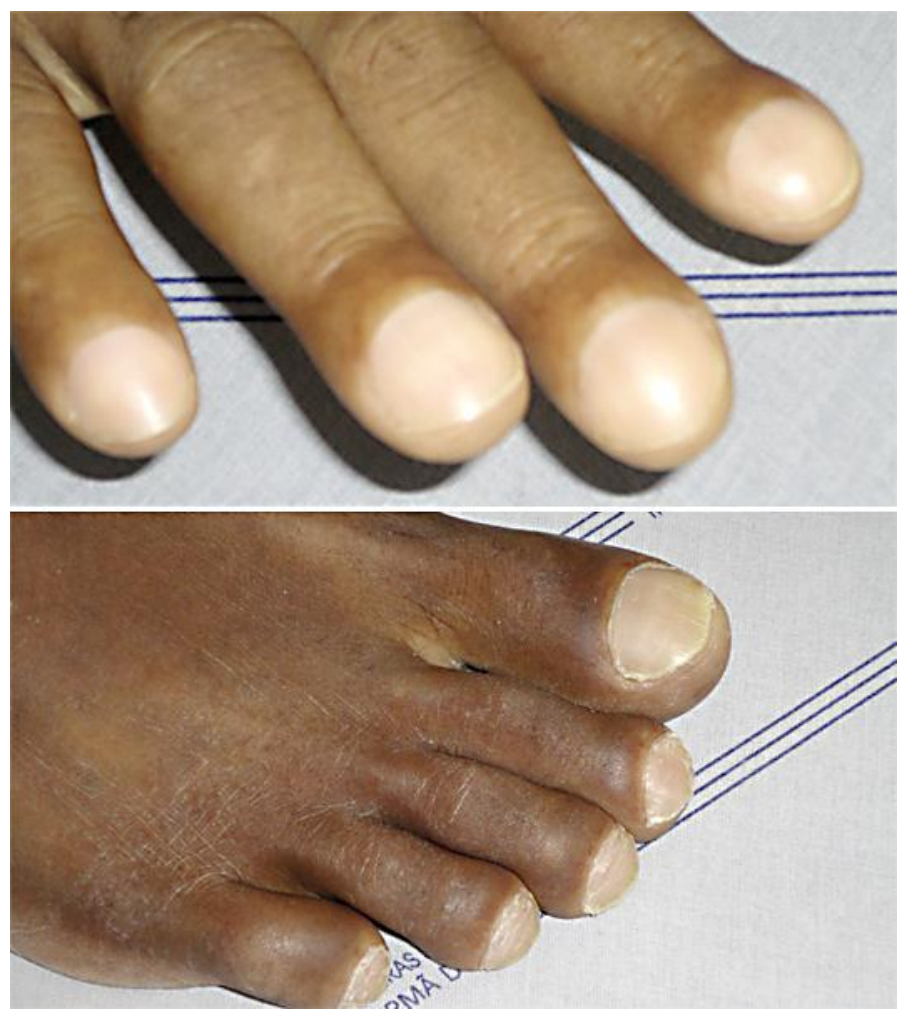

Fig. 1. Digital clubbing in hands and feet.

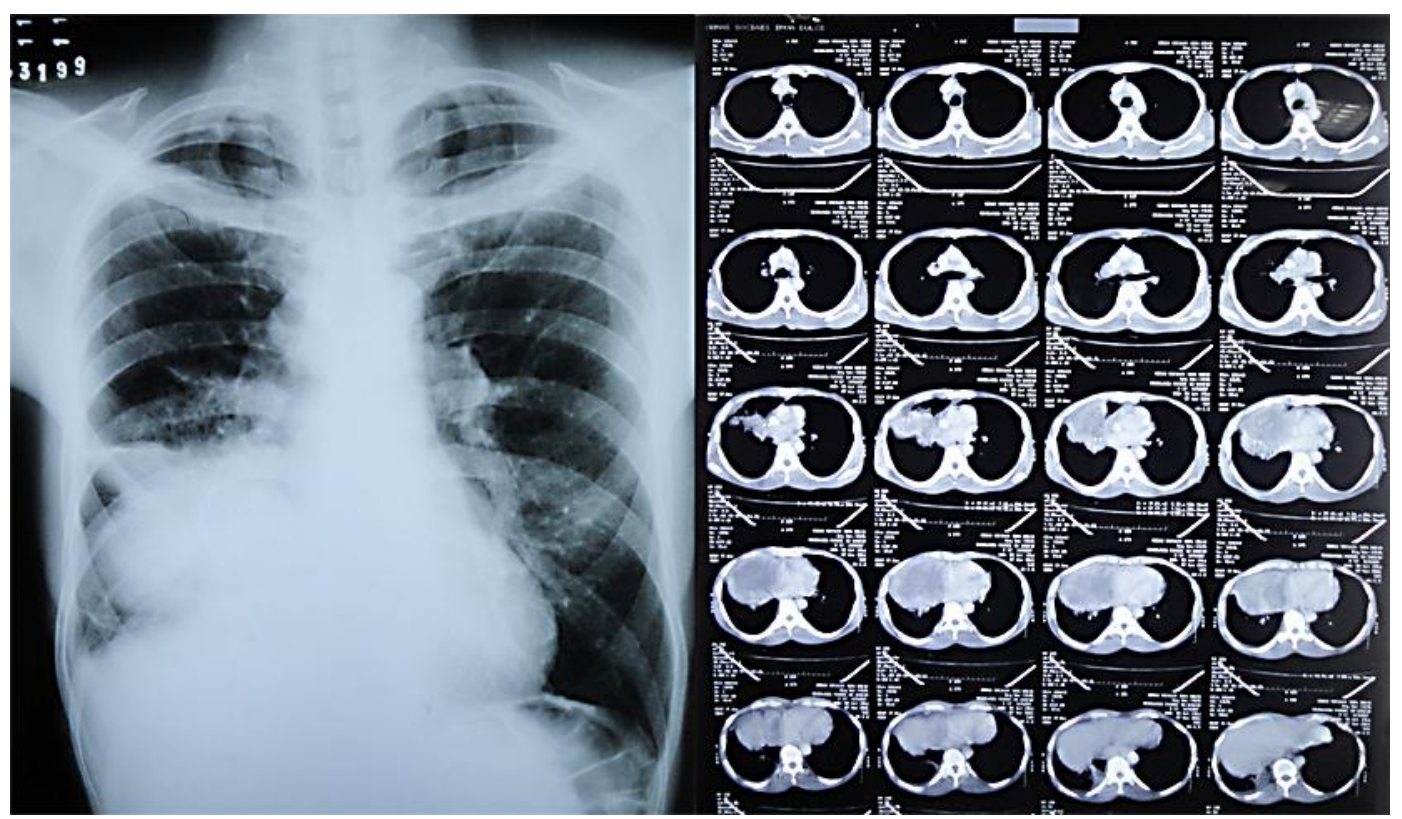

Fig. 2. Chest X-rays in AP and chest computed tomography. 


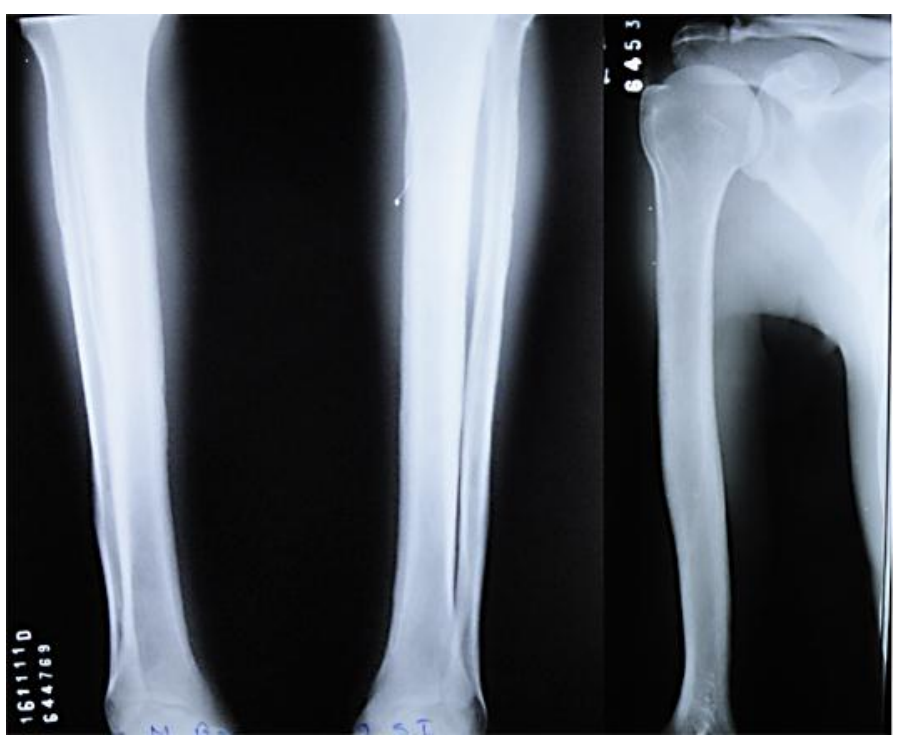

Fig. 3. Periostitis involving the right humerus and tibias bilaterally.

\section{References}

1 Ito T, Goto K, Yoh K, Niho S, Ohmatsu H, Kubota K, et al: Hypertrophic pulmonary osteoarthropathy as a paraneoplastic manifestation of lung cancer. J Thorac Oncol 2010;5:976-980.

2 Silva Júnior AF, Garcia E, Schorr F, Silva AB, Medeiros L, Silva AB: Osteopatia hipertrófica secundária a neoplasia pulmonar: Relato de caso. Rev Port de Pneumol 2009;XV:705-711.

-3 Solans-Laqué R, Pérez-Bocanegra C, Salud-Salvia A, Fonollosa-Plá V, Rodrigo MJ, Armadans L, et al: Clinical significance of antinuclear antibodies in malignant diseases: association with rheumatic and connective tissue paraneoplastic syndromes. Lupus 2004;13:159-164.

-4 Swissa M, Cohen Y, Shoenfeld Y: Autoantibodies in the sera of patients with lymphoma. Leuk Lymphoma 1992;7:117-122.

5 Madrid FF, Vandevord PJ, Yang X, Karvonen RL, Simpson PM, Kraut MJ, et al: Antinuclear antibodies as potential markers of lung cancer. Clin Cancer Res 1999;5:1393-1400.

-6 Zuber M: Positive antinuclear antibodies in malignancies. Ann Rheum Dis 1990;49:935-936.

-7 Maddison PJ, Skinner RP, Vlachoyiannopoulos P, Brennandt DM, Hough D: Antibodies to nRNP, Sm, Ro(SSA) and La(SSB) detected by ELISA: their specificity and inter-relations in connective tissue disease sera. Clin Exp Immunol 1985;62:337-345.

$>8$ Migliorini P, Baldini C, Rocchi V, Bombardieri S: Anti-Sm and anti-RNP antibodies. Autoimmunity 2005;38:47-54.

9 Azizah MR, Azila MN, Zulkifli MN, Noritta TY: The prevalence of antinuclear, Anti-dsDNA, anti-Sm and Anti-RNP antibodies in a group of healthy blood donors. Asian Pac J Allergy Immunol 1996;14:125-128.

10 Sirota P, Firer M, Schild K, Zurgil N, Barak Y, Elizur A, et al: Increased anti-Sm antibodies in schizophrenic patients and their families. Psychopharmacol and Biol Psychiat 1993;17:793-800.

11 McLean DI: Cutaneous paraneoplastic syndromes. Arch Dermatol 1986;122:765-767. 